recently treated cight cases by this last method, with results such as I bave briefly stated below.

Reports of eight cases of conical cornea treated after $\mathrm{Mr}$. Bader's method by ablation of the summit of the cone.

CASE 1.-Charles M-_ a grocer's assistant, came under my care to be treated for imperfect vision. I found the amblyopia of which he complained was due to astigmatism and marked conicity of the cornea of the left eye, the right being norinal. I determined to treat the case by removing the apex of the cone, which was done, while the patient was in a state of profound ancesthesia, by making a small flap with a Beer's catarant. knife, which was then seized with iris forcepsand cut off with a pair of fine scissors. 'The aqueous escaped the mowent the small flap was completed, the iris came in contact with the inner corneal surface, and the site of the ahlated cone apex immediately after the operation was marked by a jet black speck about the size of a pin's head, occupying the centre of the normal pupil. The eye was closed with a moist cotton-wool pad, retained in situ by a superimposed bandage, and the patient confined to bed for four days. Atropine was applied the day after the operation, no bad symptoms followed, there was no pain, and the wound healed perfectly in a month. Ultimately all trace of cone was abolished, and a minute, scarcely perceptible speck in the centre of the cornea was the only evidence of the operation. The patient, who could with difficulty decipher No. 14 Jaeger before the operation, read No. 1 Jaeger at six inches after recovery. Distant vision was also much improved. The minute speck in the centre of the coruea is scarcely perceptible, and does not interfere with vision.

CAsw 2 -Catherine $\mathrm{C}$ aged twenty-two, a healthy country girl, applied to me complaining of imperfect vision affecting the left eye. This I found on examination was due to conical cornea, which 1 treated by ablation of the summit of the cone, exactly as in the case just detailed. The wound healed in six weeks, but the result was imperfect, owing to the slight scar caused by the operation occupying the centre of the pupil. I therefore, after a delay of two months, removed a minute portion of the lower segment of the circular fibres of the iris, so as to slightly elongate the pupil downwards, and bring it oppnsite a clear portion of the cornea. Ultimately the result was perfect: all trace of cone was abolished, and the patient, who before the operation could not see anything distinctly, and was unable to decipher any ordinary print, can now see clearly, and reads newspaper type with facility. Snipping out a minute portion of the edge of the pupil in such cases has a similar effect to M. Wecker's operation of iridotomy, and is much superior to an ordinary iridectomy. The accompanving woodcut, from a sketch of the eye in questiur, shows the present shape of the pupil.

CASE 3.-John $\mathrm{H}$ - __, aged forty-seven, tailor, was gent to me to be treated for conical cornea affecting the left eye. Vision was very imperfect, even for large objects, and he had never been able to read with this eye. I excised the summit of the cone as in the preceding cases. No bad symptoms followed, although the eye was weak and watery for two months after the operation. Ultimately all trace of cone was abolisher, distant vision became very good, and the patient read rroinary newspaper type with facility. The very slight scar is only perceptible on close scrutiny, and does not interfere with vision.

CASE 4.-Master S-, aged sixteen, a young gentleman studying for the law, was brought to we by bis father on account of imperfect vision, which, it was feared, would compel him to abandon his profession. This I found was due to conicity of both cornes. I therefore operated at once on the right eye, which was slightly the worse of the two, intending to treat the left as soon as he should have recovered. Scarcely any scar is perceptible, the cone is abolished, and vision very much improved; he can now prosecute his studies with comfort-a task which before was becoming more and more difficult. A singular feature in this case is that the left eye has so much improved co. incidently with the operation on the right eye that I do not think it will be necessury to carry out my original intention of treating the cone in this eye.

CAse 5.-Mr. E-, aged thirty-six, a schoolmaster; conical corner; both eyes treated by ablation of the cone in the left. No misadventure; no bad symptoms; cone abolished; sight much improved; patient still under treatment.

Cass 6.-Eliza J_, aged twenty-three, suffering from conical cornea. This patient had been treated elsewhere by the removal of a large segment of the iris downwards and outwards in both eyes without benefit; vision was much impaired, especially in the right eye, with which the patient could barely recognise large objects. I excised the apex of the cone of this eye, and for a fortuight the case progressed favourably. During the third week after the operation, however, she had violent pain, which recurred at intervals, and was so severe as to necessitate tapping of the chamber. This patient gave me considerable trouble and anxiety, and when the wound was healed at last the sight was not in any degree benefited, although the cone was considerably reduced.

Case 7.-Samuel $\mathrm{G} \longrightarrow$, aged twenty. This patient had conical cornea to an extreme degree in the right eye, the left being normal. On testing vision prior to the operation, I found that he could with difficulty read No. 20 Jaeger with the affected eye. A month afterwards he read ordinary newspaper type with facility.

CASE 8.- Sarah Jane B-—, aged twenty. This patient was brought to me by my friend Mr. Fullargar, the well. known ophthalmic surgenn of Leicester, who kindly assisted me in the operation. Vision was failing rapidly from increasing conicity in both eyes, the left being very mucb the worse. I excised the apex of the cone in this eye. No bad symptoms followed. The cone is gradually disappearing, and vision is improved. I have no doubt that this case will be as satisfactory as the rest; but I am not able now to give particulars, as the patient has returned home, and only three weeks bave elapsed since the operation.

It will be seen from the preceding reports that $\mathbf{M r}$. Bader's operation for keratoconus yields results. In only one of the above cases was any trouble occasioned by the operation, and this I suspect was due to the excision of too large a flap of the cornea. The operation is no doubt somewhat difficult; indeed, I believe that Mr. Critchett and other eminent surgeons have expressed the opinion that it requires more dexterity than any otber which we are called upon to perform, while some (notably M. Meyer of Paris, and Dr. Williams of Cincinnati) have declared a preference for von Graefe's method, because, in their experience, Mr. Bader's operation bad been followed by extensive adhesions of the iris. I bave seen no fear, so far as my experience goes, to dread this result if the operation is carefully performed and atropine employed afterwards, while the corneal scar (always a serious objection in von Graefe's method) is so slight as to he scarcely perceptible-indeed, so slight that $I$ bave not in ang one of my cases found it necessary to tint the cornea on account of cosmetic defect.

Nottingham.

\section{ULCERATING SYPHILIDE IN A CHILD TWELVE YEARS OLD.}

BY EDWARD I. SPARKS, M.A., M.B. Oxon., M.R.C.P., PGYBICIAN FOR TEI TREATMENT OF DISEABES OP THB SKIN, CHARINGCross hospital; Paysictan TO ST GEORgE's (HANOVERSQUAIR) DISPEASARY.

M. E-, a girl, aged twelve years, came to me as an out-patient at Charing-cross Hospital on June 14th, 1873, with an erupsion on the trunk and extremities of three weeks' standing. Her mother was certain that she had had nothing the matter with her before that time. T'he child was in a very miserable state, pale and thin, and with a worn, anxious expression of countenance. She had evidently been neglected, was badly clothed, and her head swarmed with pediculi. Her back, from the nape of the neck downwards to the sacrum, was covere 1 with numerous slightlyraised, circular, reddish-brown, flat papules, varying in size from a split pea to a shilling, and very faintly silvered with thin scales. The neck and shoulders were most affected. 


\section{Thr Lanomi, ]}

In smaller numbers papules of the same kind studded the front of her chest and abdomen, and there were a few on the arms and insides of the thighs. The outsides of the knees and elbows and the face were absolutely free, but there were a few papules on the hairy scalp. The eruption, as far as already described, had thus the appearance of a lenticular syphilide. What, however, gave peculiar interest to the case was the presence of several large, sharply-cut ulcers, with foul, yellowish base, and coppery-red edges, intermingled with the papules on different parts of the body-for example, over the sternum, on the right shoulder, and in the right groin. These ulcers varied in size from a shilling to a five-shilling piece, and some of the largest were covered with greenish-black, irregular, lava-like crusts, from half an inch to nearly an inch in height. The formation of crusts was prevented in many places by the friction of the clothes or the movements of the body, but all the ulcers secreted the same kind of foul purulent fluid. There was no sign of a vesicle, bulla, or true pustule anywhere. The mode of formation of the ulcers from the papules could be clearly traced on the back, the thin scale covering each being detached by slight exudation beneath it, leaving a moist surface, which then ulcerated and crusted. The sores did not give much pain or irritation of any kind. There was no falling of the hair, no iritis, and no sign of keratitis. The child had not suffered from headaches lately, and, though always delicate, had had no serious previous illness. Her throat was not subjectively sore, though her mother stated that she had lately appeared to swallow her food with some difficulty. On examination only slight redness and a very superficial ulceration of the posterior wall of the pharynx on the left side was found. She had no mucous patches in the mouth or at the commissures of the lips, though later on she had one or two inside the lips. There was some indolent enlargement of the glands in the groins, especially on the left side (possibly due to the irritation of the neighbouring ulcers), and also of a small postnuchal gland, but there was no enlargement of the submaxillary glands. There were no sores or mucous tubercles about the anus or vulva. The hymen appeared to be absent, but there was no redness of, nor discharge from, the genitals, nor had there ever been. The girl had never menstruated.

There was no doubt in the mind of anjone who saw her that she was suffering from the effects of syphilis; but some were inclined to think the syphilis hereditary, and not acquired. My own view from the first was that it was acquired, judging from the character of the eruption, the child's age, and the absence of all symptoms of hereditary syphilis in early life. She had also been in the way of possible contagion, having, according to her mother, for the last two years acted as a servant to some women of questionable character, who occupied a house in the same street, so that she might have caught it from them. The question of immoral infection was not mooted before her, though it must not be overlooked. I will here give the negative evidence obtained with regard to the hereditary nature of her symptoms, and leave the discussion of probable inheritance in the present case till later on in the paper.

The father is and always has been healthy. The mother has never had any illness except her confinements, nor any sores or eruption on her body. She has had fourteen children, of whom seven are alive, and four of these were born in succession previous to the patient. There are two healthy younger children. Of the dead children, two were her very first: a baby which died a month after birth, but without any symptoms of congenital syphilis; and a miscarriage at four months. Of the others now dead who were born since M. E-, one was a cross-birth, and the four others died of small-pox, whooping-cough, bronchitis, and scarlet fever respectively. The child herself presents no marks of inherited syphilis in her physiognomy, corneæ, or dentition; the central incisors are well formed in every respect, as well as her other teeth.

As it was found impossible for her to get the food and care she needed at home, she was taken into the hospital on June 21st, 1873 . It will not be necessary to enter into her treatment at great length, but I may say that she had one twentieth part of a grain of bicyanide of mercury every night, and twenty minims of syrup of the iodide of iron three times a day. She was allowed as much nourishing food as she could digest, and had half a pint of stout, and
[JUNE 20, 1874.

afterwards three ounces of wine, and one drachm of cod-liver oil three times a day. The ulcers, after removal of all crusts, were dressed with an ointment of red oxide of mercury (eight grains to the ounce), which was found to answer better than several other applications which were tried. The child was obliged to be put on a water cushion, and for a long time could wear no nightdress, but the nurse contrived to keep her warm by using large pieces of lint for the dressings. Her appetite was good, and she slept well. From the time of admission she made steady progress, and not a single fresh papule or ulcer appeared, and the old ones healed up uninterruptedly. The mercury was continued in the small dose of one-twentieth of a grain till August 9th, when, as most of the ulcers were nearly healed, it was discontinued, but, as a marked diminution in the rapidity of their progress (noticed even by the nurse) took place, it was resorted to again on August 30th. Iron in some form was given throughoul. Iodide of potassium in three-grain doses, at one time substituted for the syrup of the iodide on account of diarrhoa, did not suit her; it also gave her diarrhoa, and brought out an erythema and some flattish pustules on the back. The girl went out on September 9th with only a slight scab on the right shoulder. All the ulcers had left smooth scars, and even some of the spots which were only superficially moist after removal of their scabs, had left very shallow ones. She was now able to get about as usual and work with her needle, and showed signs of considerable quickness and intelligence. She was seen again on November 13th, and appeared in excellent health. She had bad no return of the eruption in any form. Directions were given to her mother to bring her at once to the hospital in case of a relapse, but she has not returned.

There are several points of interest in this case. Acquired syphilis is very rare in so young a child, and very few cases. of the ulcerative or rupial form have been recorded in children. Cullerier* says, "for myself I have never had the opportunity of observing a single case of rupia in syphilitic children," and Zeissit says he has " with his large opportunities seen extraordinarily few such cases." The same author remarkst that he has never yet seen rupia either in infants or in older children who have suffered from congenital syphilis; but, on the other hand, be could always " in those rare cases where it occurred in children nearing puberty (erwachsenen Kindern) find the locus infectionis," and he is therefore convinced that rupia is always a sequel of acquired syphilis. I allude here to the question of hereditary syphilis, not from any belief in its existence in the present instance, but because others who saw the case seemed to incline to that view, and it therefore seems right to point out that, as far as present evidence goes, rupia in children is never of congenital origin. I must particularly call attention to the absence of all history of early infantile syphilis here, and also to the admixture of a secondary papular eruption with the crusting ulcers, for Mr. Hutchinson § says, "If any symptoms of (inherited) syphilis occur in infancy, they will be of the secondary group, and if none of this group occur at that age they will not appear at a later one;" and Mr. Berkeley Hill, in a note he has been kind enough to send me, says, "as far as observation goes, inherited syphilis does not show itself at twelve years of age as papular, dry, or ulcerating papular affections, without some more unmistakable pseudo-scrofulous disease, such as periostitis, subcutaneous gummata, inflammation of the lymphatic glands, or the like."

In this case no certain locus infectionis could be discovered, even after careful examination; but MIr. Cooper Forster|| has also reported two cases of ecthymatous syphilis in young persons of seventeen and nineteen years of age, in neither of which was there any history of a primary sore, though "neither could possibly be mistaken for a disease unconnected with a syphilitic taint." Mr. Cooper Forster adds that in his experience an inherited syphilitic taint is only manifested in the offspring in adult life, or after puberty, as one of the severer kinds of tertiary disease, and not as a skin, eruption." This remark might no doubt be equally well applied to the present case.

A feature of interest here is the rapid progress which

* Cullerier and Bumstead's Atlas of Venereal Diseases, p. 2r9. + Die Constitutionelle Syphilis, s. 172.

Loa. cit., s. 171.

Syphilitic Diseases of the Eye and Ear, Aphorism xxxriii,

Guy's Hospital Reporta, 1873, p. 35. 
the disease made in the short space of three weeks from its commencement. Bazin has, under the name of "syphilides malignes précoces forme tuberculo-ulcérante gangréneuse," ** described an eruption almost identical in all its symptoms.

As to the question of the dependence of the ulcerations on previous cachexia, though the child had been neglected, yet there is no bistory of failing health before the eruption appeared, and $\mathrm{Mr}$. C. Forster distinctly states that in his cases the idea of cachexia as a predisposing cause could be certainly excluded.

In conclusion, I may say, with regard to the treatment, that mercury was given on account of (1) the previous short duration of the disease, (2) the intermixture of secondary with so-called tertiary eruption, and because (3) this appeared to be the first manifestation of syphilis the patient had ever had. The bicyanide was chosen merely as an unirritating preparation, and as the one which I am most accustomed to use.

There has been until lately such a general agreement among writers on syphilis that mercury is injurious in the severer ulcerative forms of syphilis, that it is gratifying to me to have the support of Mr. Jonathan Hutchinson, in his recent papers on Syphilis, in favour of such a treatment as was adopted in the case here discussed.

\section{AN INHALER FOR NITRITE OF AMYL.}

By CHARLES J. SMITH,

TATE SURGRON TO THE FARRINGDON DISPBNSARY, BBSIDETT MRDICAL OFFICER TO THE HOSPITAL FOR THE PARALYSED AND EPILEPTIC.

Maring very constant use of Dr. Richardson's invaluable discovery, nitrite of amyl, the primitive methods of exhibiting it soon struck me as being wasteful and unscientific, and $I$ turned about how best it could he administered with $a$ due regard to saving and convenience; it being on the one hand an expensive remedy, while on the other so many cases demand its very rapid and thorough administration, notably angina pectoris.

I submitted sketches of an instrument, which $I$ thought would supply all the elements of a successful inhaler, to Messrs. Krobne and Sesemann, of Duke-street, Manchestersquare, and they, taking infinite trouble, have perfectly carried out my views in the inhaler, of which a woodcut, admirably drawn by Mr. Arthur Hunt, is appended.

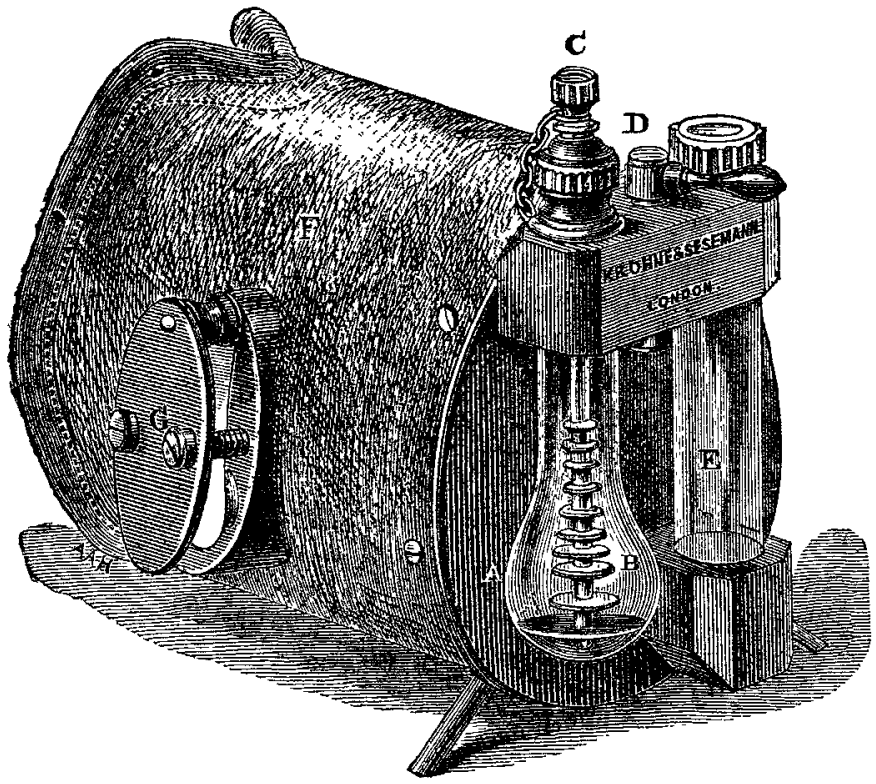

This inhaler consists of a leathern portion ( $F$ ), which fits over the nose and mouth of the patient, and of two glass chambers ( $A$ and $E$ ) connected with each other by a tap (D). $A$ is a bulbous glass reservoir, containing the nitrite of amyl; it has a small glass tube (B) covered with flannel flanges to prevent the amyl slopping over into the second chamber (E), and is furnished with a plug (c). D is a tap which permits communication between the two chambers. is the second chamber, into which the amyl vapour passes * La Syphilis et les Syphilides, p. 385. prior to inhalation; this communicates with the leathern portion of the inhaler. To prevent the patient breathing back, or coughing into the reservoir, a tube valve guards the point of communication. $a$ is a shield over a talc valve which gives free egress to expired air, while on the opposite side, not shown in the woodcut, is a slot to regulate the admission of additional pure air when necessary.

The inhaler being kept charged, the patient in using it needs simply to pull out the plug $c$ at the same time that he turns the tap $\mathrm{D}$ towards the reservoir; he then inhales. Air passes by the vent tube $B$ through the ampl, becomes charged with the vapour, and passes over into the chamber $E$; thence to the body of the inhaler, and is inspired. Expiration following, the valve which guards E closes, while the valve under $a$ opens, and permits the escape of the expired air.

There is absolutely no danger in this inhalation of amyl, the patient ceasing to inhale so soon as he experiences relief.

It was found necessary to use vulcanite for the various parts of the instrument, as no metal was able to resist the powerful corrosive effects of the amyl, whether electroplated, nickel silver, or gold; and it is further curious that this substance should produce no effect upon vulcanite, while chloroform is rapidly fatal to it.

That this substance should have met with such neglect at the hands of the profession appears incomprehensible, for I venture to affirm that a more important agent has never been discovered; and I would urge practitioners to make frequent use of it, and record the results, especially in cases of so-called neuralgia, toothaches, certain earaches, and particularly in angina pectoris, whose pangs are almost instantly checked by it.

There is every reason to hope for the best possible results in tetanus if amyl is early resorted to and earnestly persevered with, while heart affections might be benefited to an extent scarcely to be credited.

\section{ditlirror}

\section{HOSPITAL PRACTICE, BRITISH AND FOREIGN.}

Nulla autem est alia pro certo noscendi via, nisi quamplurimas et morborum et dissectionum historias, tum aliorum, tum proprias collectas habere, et inter se comparare.-MobgaGNI De Sed.et Caus. Morb., lib. iv. Procmium.

\section{CHARING-CROSS HOSPITAL.}

CASE OF SEVERE CHOREA TREATED BY THE INHALATION OF CHLOROFORM.

(Under the care of Dr. Julrus Pollock.)

WHEN speaking (at p. 728) of the difficulties and obscurities which attend the pathology and treatment of chorea, we warned against the danger of accepting the logical fallacy of post hoc ergo propter hoc in estimating the value and effects of any remedial agent administered during the course of this disease. The remarks which were then made applied to a case of chorea which was benefited in a most marked manner by large and frequent doses of chloral hydrate, after the failure of perchloride of iron and of the hydrochloric solution of arsenic. On the other hand, it will be seen that in the subjoined case both chloral hydrate and the bromide of potassium signally failed to produce any diminution of the distressing symptoms, whereas after the inhalation of chloroform the symptoms gradually abated and eventually almost entirely disappeared. Such inconsistency of experience must be only apparent. When we shall have become possessed of a knowledge of the laws and the conditions which regulate and determine the choreic instability of nerve and muscle, we shall doubtless possess also the means for its arrest and removal.

E. C- aged eleven, was admitted into Charing-cross Hospital on the 31st March, 1874, suffering from chorea. She states that she has never had a similar attack before. There is no history of acu te rheumatism; no heart affection. She had measles "a long time ago," and, before that, bronchitis and whooping-cough. The present illness began three weeks before admission, and followed a fright. She gaw her 